\title{
UNA DEFENSA DEL CONVENCIONALISMO JURÍDICO *
}

\author{
Josep M. Vilajosana \\ Universitat Pompeu Fabra (Barcelona)
}

RESUMEN. Este trabajo muestra que la existencia de un sistema jurídico requiere la presencia de una práctica unitaria de identificación de normas. El autor sostiene que esa práctica consiste en una convención constitutiva, que permite identificar de manera autónoma el Derecho de una determinada comunidad. Se pone de relieve de este modo una forma específica en que el Derecho es una creación social: del mismo modo que la existencia del dinero requiere la creencia de que éste existe, también la existencia de un sistema jurídico depende, en última instancia, de un conjunto de creencias compartido por las personas relevantes. El planteamiento de esta posición y de sus ventajas se lleva a cabo a lo largo de los apartados 2, 3, 4 y 5 . El último apartado se dedica a examinar y a descartar cinco posibles objeciones a una tesis convencionalista como la que aquí se defiende.

Palabras clave: hechos sociales, convención, existencia del Derecho, realidad social, convencionalismo, regla de reconocimiento, reglas constitutivas.

ABSTRACT. This paper shows that the existence of a legal system requires the presence of a unitary practice of identification of rules. The author holds that this practice consists of a constitutive convention, which allows identifying the Law of a determinate community in an autonomous way. A specific way in which the Law is a social creation is like the existence of money. Money exists only if people believe that it exists, and also the existence of a legal system depends, ultimately, on a set of beliefs shared by the relevant persons. The conventionalist thesis that is defended here develops in sections 2, 3, 4 and 5, highlighting its advantages. In the last section five possible objections are rejected.

Keywords: social facts, convention, existence of Law, social reality, conventionalism, rule of recognition, constitutive rules.

\footnotetext{
* Fecha de recepción: 24 de febrero de 2010. Fecha de aceptación: 28 de marzo de 2010.
} 


\section{INTRODUCCIÓN ${ }^{1}$}

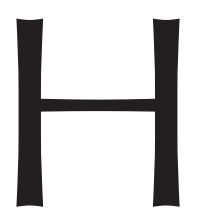

ay usos muy distintos de la palabra «convención» y no todos ellos son relevantes en esta sede. Podría decirse que el sentido más general en el que suele hablarse de que algo es convencional consiste en equipararlo a algo que es artificial (una creación humana) y contraponerlo a lo que es natural (algo cuya existencia no dependería de la intervención de los seres humanos). Pero, al ser tan general, este concepto de convención resulta poco apropiado para dar cuenta de fenómenos sociales característicos como el Derecho. De hecho, todos los fenómenos sociales, justamente por no ser naturales, serían en este sentido convencionales. De ahí que las convenciones de las que se suele hablar en teoría del Derecho tengan que ver con hechos sociales, pero con algún rasgo adicional.

Como una primera aproximación, que más adelante matizaré, se entiende que los hechos sociales consisten en una serie de conductas de los miembros de una determinada sociedad con una característica básica: se trata de acciones que se realizan teniendo en cuenta la conducta de los demás. Adicionalmente, el rasgo convencional surge cuando se puede formular con sentido y para cada comportamiento verbal y no verbal de los participantes un contrafáctico como éste: «Si los demás no dijesen y no hiciesen lo que hacen yo no diría lo que digo o haría lo que hago». Ésta ya es una forma específica de considerar las convenciones y que no es meramente equiparable a lo que sea artificial o social. Más bien, la contraposición ahora ya no es entre lo social y lo natural, sino, dentro ya de lo social, entre lo que es reflejo de una convención (que sería lo que acabamos de ver) y lo que es fruto de una convicción. Esto último podría ser representado a través de un contrafáctico que correría paralelo al anterior: «aunque nadie dijese lo que dice o hiciese lo que hace, yo diría lo que digo o haría lo que hago» ${ }^{2}$.

La discusión actual acerca del carácter convencional del Derecho tiene más bien que ver con este sentido y arranca de la toma en consideración del trabajo del filósofo D. LEWIS, On Convention, en el que se trata técnicamente el concepto de convención vinculándolo a la literatura acerca de teoría de los juegos y el análisis de las decisiones estratégicas. De ahí pasó a la teoría del Derecho, básicamente a través de la interpretación de la regla de reconocimiento de HART como una convención en el sentido de LEWIS. Aunque con algunas diferencias significativas entre ellos, se puede rastrear esa historia a través de los trabajos pioneros de UlLmann-Margalit (1977) y de PosTEMA (1982), hasta llegar a los más recientes de LAGERSPETZ (1995), MARMOR (1996), SHAPIRO (2001) y COLEMAN (2001). Entre nosotros también se han dado pasos en esta dirección ${ }^{3}$.

Ahora bien, como ha indicado BAYÓN, el rótulo «convencionalismo» puede ser usado en dos sentidos diferentes ${ }^{4}$. En uno de ellos, hablaría sólo de las condiciones de

${ }^{1}$ La investigación para este trabajo ha sido parcialmente financiada por el Ministerio de Educación y Ciencia, con una ayuda del programa CONSOLIDER INGENIO 2010 (CSD2009-0056).

2 La formulación de estos contrafácticos la tomo de NARVÁEZ, 2004: 280.

3 Hay que destacar los trabajos de J. C. BAYÓN y de M. NARVÁEZ, citados a lo largo de este trabajo. También puede verse Vilajosana, 2003: 2006.

4 BAYÓN, 2001. 
existencia del Derecho, afirmando que éste consiste en una realidad convencional, en un producto de interacciones humanas. Pero no todas las reglas convencionales serían convencionales en el mismo sentido: sólo algunas reglas convencionales -en el sentido lato que equivale a reglas sociales- serían específicamente convenciones en el sentido técnico que es familiar en teoría de juegos a partir de la obra citada de LEWIS, esto es, como una solución a un problema de coordinación. En tal sentido, una convención puede ser vista a la vez como un hecho social y un entramado de razones para actuar, lo que ha llevado a algunos autores a sostener que la regla de reconocimiento de un sistema jurídico es una convención de esta clase, como modo de reconciliar el carácter social y la normatividad del Derecho. Esta última acepción del convencionalismo sería no ya relativa a las condiciones de existencia del Derecho, sino a su normatividad.

En este trabajo me referiré básicamente al primer sentido, si bien aludiré en su momento a algunos problemas que se esconden tras la pregunta acerca de la normatividad. En lo que sigue mostraré que la existencia del Derecho en una determinada sociedad requiere la presencia de una práctica unitaria de identificación de normas. Sostendré que esa práctica consiste en una convención constitutiva, que permite identificar de manera autónoma el Derecho de una determinada comunidad. Espero poner de relieve de este modo una forma específica en que el Derecho es una creación social: del mismo modo que la existencia del dinero requiere la creencia de que éste existe, también la existencia de un sistema jurídico depende, en última instancia, de un conjunto de creencias compartido por las personas relevantes. El planteamiento de esta posición y de sus ventajas la llevaré a cabo a lo largo de los apartados 2, 3, 4 y 5. El último apartado lo dedicaré a examinar y a descartar cinco posibles objeciones a una tesis convencionalista como la que aquí defiendo.

\section{LA TESIS SOCIAL}

Pocas dudas caben acerca de que el Derecho es un fenómeno social. Una forma de expresarlo es que, de algún modo, el Derecho depende de hechos sociales.

Sin embargo, en la literatura sobre la relación entre hechos sociales y Derecho se puede apreciar una gran variedad terminológica y de contenido. Sólo para tomar alguna muestra representativa de la teoría del Derecho contemporánea, mencionaré algunas definiciones que pretenden recoger intuiciones parecidas.

Por ejemplo, RAz habla de «la tesis de las fuentes sociales» al decir que «una teoría del Derecho es aceptable sólo si su test de identificación del contenido del Derecho y determinación de su existencia depende exclusivamente de hechos sobre la conducta humana susceptibles de ser descritos en términos valorativamente neutrales y aplicados sin recurrir a ningún argumento moral» ${ }^{5}$.

Por su lado, Postema sostiene lo que llama «tesis social»: «El Derecho es un hecho social; lo que cuenta como Derecho y lo que no, es material de hecho acerca de la conducta social humana e instituciones que pueden ser descritas en términos que no impliquen ninguna evaluación de la conducta de las instituciones. Entendemos el

5 RAZ, 1979: 41-42 y 47. 
Derecho sólo si lo entendemos como una clase de institución social que puede decirse que existe sólo si es realmente vigente y dirige la conducta humana en la comunidad. Toda teoría general del Derecho que sea adecuada debe ofrecer una aproximación satisfactoria del Derecho como fenómeno social» ${ }^{6}$.

COLEMAN ha dado el nombre de «tesis de los hechos sociales» a aquella que pretendería sostener que «siendo el Derecho una práctica social normativa, es hecho posible por algún conjunto de hechos sociales» ${ }^{7}$.

Por último, ZIPURSKY ha hablado de «modelo de los hechos sociales» para referirse al que sostendría quien afirmase que «una proposición jurídica es verdadera de acuerdo con ciertos hechos sociales» ${ }^{8}$.

Este elenco, por supuesto, carece de pretensión exhaustiva, pero ayuda a poner de relieve dos cosas. En primer lugar, no sólo la presencia de una nomenclatura variada, sino la diversidad de intereses cognoscitivos que están en juego. Así, mientras unos enfatizan los aspectos ontológicos, otros toman en cuenta las cuestiones epistemológicas, cuando no semánticas o metodológicas. Y todo ello, a veces, dentro de la misma definición. Así ocurre, emblemáticamente, con la formulación de la tesis social de POSTEMA, cuya primera parte contiene una tesis ontológica («El Derecho es un hecho social...»), sigue con una tesis epistemológica («Entendemos el Derecho...») y culmina con una tesis metodológica («Toda teoría general del Derecho que sea adecuada debe...»).

En segundo lugar, y después de todo, tal vez se dé alguna coincidencia entre ellos. Este mínimo punto en común podría ser una versión ontológica de la Tesis social (TS), sobre cuya elucidación versarán las páginas que siguen y que puede enunciarse así:

(TS): La existencia del Derecho depende de la existencia de determinados hechos sociales.

A su vez, (TS) requiere un ulterior examen, que establezca cuál es la relación de dependencia que se predica y en qué consisten los hechos sociales a los que se alude?

\section{LA RELACIÓN DE DEPENDENCIA ENTRE HECHOS SOCIALES Y DERECHO}

Respecto a la naturaleza de las entidades a las que se alude en (TS), se pueden adoptar básicamente dos posiciones. Una, que podemos llamar reduccionista, sostendría que las normas jurídicas son hechos sociales y el Derecho, por tanto, está formado por hechos sociales ${ }^{10}$. Otra, que llamaríamos no reduccionista, en cambio, entendería que de alguna forma las normas jurídicas y, con ellas, el sistema jurídico de una deter-

6 Postema, 1982: 165.

7 COLEMAN, 1982: 395.

8 ZIPURSKY, 2001: 225.

9 La tesis social puede ser interpretada de dos maneras distintas. Una, como fundamento de enunciados jurídicos externos (en la terminología de HART); otra, como base de los enunciados jurídicos internos. Vaya por delante que lo que aquí interesa es la primera de estas dos interpretaciones, como creo poner de relieve a lo largo del texto. Para apreciar las dificultades de la segunda interpretación, vid. ToH, 2008.

10 Ésta es, como se sabe, la posición de OliveCrONA, al menos en la primera edición de su famoso libro, Law as Fact. Cfr. OliveCronA, 1939. 
minada comunidad superviene a determinados hechos sociales sin identificarse con ellos ${ }^{11}$. No voy a discutir más sobre esta cuestión ${ }^{12}$. Baste decir por ahora que esta segunda posición, mayoritaria en la doctrina iusfilosófica actual, será la presupuesta en este trabajo, por cuanto supone una adaptación a la práctica lingüística de los juristas $^{13}$.

Sin embargo, a los efectos de clarificar la relación de dependencia entre hechos sociales y Derecho que se postula en la Tesis social no basta con acordar que el Derecho superviene a determinados hechos sociales. Se requiere, además, profundizar en el análisis de esta relación. En efecto, puede sostenerse que la existencia de determinados hechos sociales es o bien condición necesaria o bien condición necesaria y suficiente de la superveniencia del Derecho.

Si se mantiene que la existencia de hechos sociales es condición necesaria, pero no suficiente, de la superveniencia del Derecho, lo que se afirma es que sin determinados comportamientos y actitudes de los seres humanos de una determinada sociedad no existiría el Derecho de esa sociedad, pero que tales conductas y actitudes no son lo único que se requiere para dar lugar a los sistemas jurídicos. Se puede exigir, por ejemplo, que el contenido de las normas dictadas a partir de un determinado procedimiento no contradiga lo dispuesto en un Derecho ideal o racional. Si (TS) se interpreta de esta forma, podría ser una tesis perfectamente aceptada por la mayor parte de los autores no positivistas, ya que éstos no niegan que deban darse algunos hechos sociales para identificar el Derecho de una determinada sociedad (¿cómo si no podríamos distinguir el Derecho de la sociedad $A$ del Derecho de la sociedad $B$ ?). Lo que no aceptan estos autores es que eso sea lo único que se requiera para desarrollar tal identificación ${ }^{14}$.

Por tanto, lo que aquí se dirá debería ser de utilidad tanto para positivistas como para no positivistas, ya que la indagación es acerca de las condiciones de existencia del Derecho positivo. Parafraseando a BAYÓN, lo que aquí sostengo no es una tesis acerca del contenido mínimo del positivismo, sino más bien una tesis sobre el contenido mínimo del Derecho positivo ${ }^{15}$.

Si se mantiene que la existencia de hechos sociales es condición necesaria y suficiente de la superveniencia del Derecho, lo que se afirma es que sin determinados comportamientos y actitudes de los seres humanos de una determinada sociedad no existiría el Derecho de esa sociedad y que tales conductas y actitudes son lo único que se requiere

11 Vid., por todos, Coleman, 2001. Podría decirse que ello ocurre, por ejemplo, en el sentido de las normas-prescripción.

12 En puridad, se podrían sostener dos posiciones no reduccionistas. Una, eliminativista, que consistiría en sostener que puesto que no cabe la reducción y no hay más entes que los empíricos, entonces en ningún sentido significativo se puede decir que las normas jurídicas existen; otra, emergentista, que admitiría que hay un espacio para los entes normativos. La visión de la superveniencia de las normas jurídicas que se defiende en el texto vendría a ser una versión del emergentismo. Para esta terminología, algo adaptada, vid. NETA, 2004: 200. Para una posición emergentista, pero con distinto alcance del que aquí se defiende, $c f r$. GREENBERG, 2004.

13 Vid., en esta línea, por ejemplo, PeCZENIK y Hage, 1999.

14 Piénsese, por poner sólo dos ejemplos significativos, en el «derecho humano» del que habla TOMÁs DE AQuino (Summa Theologica, I-II, 90, y 95 a 1), o el Derecho en su «etapa preinterpretativa», en palabras de DWORKIN: «First, there must be a "preinterpretative" stage in which the rules and standards taken to provide the tentative content of the practice are identified» (DWORKIN, 1986: 65-66).

${ }^{15}$ El título del trabajo de BAYÓN al que hago referencia es «El contenido mínimo del positivismo jurídico». Cfr. BAYÓN, 2001. 
para dar lugar a los sistemas jurídicos. Ésta es seguramente la posición que identifica más claramente al positivismo jurídico y en la que no pueden estar de acuerdo ni los autores iusnaturalistas ni DwORKIN. Prescindo aquí de la división dentro del positivismo de los llamados positivismo «incluyente» y «excluyente». Para dar cuenta de esta discusión se requiere una posterior distinción entre las condiciones de existencia de los criterios de pertenencia de las normas a un determinado sistema jurídico y el contenido de esos criterios. Para el positivismo excluyente ambas cuestiones remiten necesariamente a hechos sociales; para el positivismo incluyente, los hechos sociales sólo tienen que aparecer necesariamente como condiciones de existencia de los criterios, pero no del contenido de los mismos ${ }^{16}$.

\section{HECHOS SOCIALES}

\subsection{Hecho social y hecho convencional}

Qué quepa entender por «hecho social» es una cuestión nada clara en la literatura filosófica general ${ }^{17}$ y en la iusfilosófica en particular. Así, no resulta infrecuente encontrar en un mismo texto distintos usos, muchas veces sólo implícitos, de esta expresión. Por lo que ahora nos concierne, pueden distinguirse dos sentidos que podemos llamar general y particular.

En sentido general, con la expresión «hechos sociales» se haría referencia a los comportamientos, actitudes y creencias de las personas que viven en sociedad. En sentido particular, se reservaría la expresión «hecho social» para una subclase de esos comportamientos, actitudes y creencias, caracterizada por la presencia, entre otros rasgos a los que después aludiré, de «creencias mutuas» ${ }^{18}$, «intencionalidad colectiva» ${ }^{19}$, «conocimiento común» ${ }^{20} \mathrm{o}$ «razones interdependientes» ${ }^{21}$.

Los dos sentidos son relevantes para la teoría del Derecho, pero conviene no confundirlos. En efecto, únicamente si se emplea el sentido general cabe luego la posibilidad de decir que autores tan emblemáticos del positivismo jurídico como son AUSTIN y HART mantienen la Tesis social, puesto que entendido «hecho social» en su sentido particular, tal tesis sería sostenida por HART, pero tal vez no por AusTin. Es, en efecto, central a la teoría del Derecho hartiana la presencia del punto de vista interno, que en mi opinión, como veremos, remite necesariamente al concepto de creencia mutua o de conocimiento común. La doctrina de Austin, en cambio, se caracteriza por dar una explicación del fenómeno jurídico en términos de hábito de obediencia, que precisamente no requiere la presencia de tal elemento ${ }^{22}$.

16 Por tanto, tampoco entraré a discutir si la visión convencionalista del Derecho es compatible o no con el positivismo incluyente. En contra de esta posibilidad, $c f r$. DwORKIN, 1986: 124-130; a favor, $c f r$. CoLEMAN, 1998.

17 Para un análisis exhaustivo del concepto de hecho social, vid. GILBERT, 1989.

18 En terminología, por ejemplo, de LAGERSPETZ. Cfr. LAGERSPETZ, 1995.

19 Por usar la expresión de SEARLe. $C f r$. Searle, 1995.

20 En palabras de LewIS. Cfr. LEWIS, 1969.

${ }^{21}$ Cfr. Hartogh, 2002.

22 Cfr. Austin, 1832, especialmente Lección 6. 
Si esto es así, habría una buena razón para trazar la distinción entre Tesis social y Tesis convencionalista en este punto. La Tesis social (TS) haría referencia a hechos sociales en general, mientras que la Tesis convencionalista sería una especificación de (TS) que se caracterizaría por aludir a hechos sociales en sentido particular a los que llamaríamos hechos convencionales, que serían así una subclase de hechos sociales.

Concretando más, si tomamos como Universo del Discurso la clase de los hechos, éstos pueden dividirse entre hechos naturales y hechos sociales. Los primeros son aquellos cuya existencia es independiente de cualquier estado intencional (creencias, deseos, actitudes), mientras que los segundos son dependientes de estados intencionales colectivos ${ }^{23}$. Estos últimos, a su vez, pueden dividirse entre hechos convencionales y hechos no convencionales.

Los hechos convencionales se caracterizan por la presencia de un comportamiento recurrente, por creencias acerca del mismo que constituyen una razón para seguir dicho comportamiento y por un conjunto de expectativas generadas a partir del conocimiento común de estas circunstancias. Esta caracterización puede concretarse a través de las siguientes cláusulas ${ }^{24}$ :

1. La mayoría de los miembros de un determinado grupo realiza una determinada conducta cuando se dan determinadas circunstancias.

2. La mayoría de los miembros del grupo cree que 1.

3. La creencia de que se da 1 constituye una razón para realizar esa conducta en esas circunstancias.

4. Hay un conocimiento común entre la mayoría de los miembros del grupo de lo que se dice en las anteriores cláusulas. Es decir, las conocen, conocen que los demás las conocen, conocen que los demás conocen que ellos las conocen, etcétera.

La primera cláusula apunta a la necesidad de que se dé un comportamiento recurrente. Ello excluye, por ejemplo, que puedan darse convenciones de un solo acto, lo que en teoría de juegos serían juegos de una sola tirada. Se precisa, pues, un comportamiento regular.

La segunda cláusula tiene en cuenta el carácter consciente de esa práctica regular. Con ello se descarta que el comportamiento recurrente al que se refiere la primera cláusula pueda darse de forma azarosa: cuando se da un hecho convencional, los participantes que lo generan son conscientes de que su conducta genera esta regularidad de comportamiento.

La tercera cláusula es de la máxima relevancia. Es la que nos permite establecer la diferencia entre actuar por convención y actuar por convicción. Tal como ya dije anteriormente, para alguien que actúa por convicción, lo que hagan los demás no resulta relevante para su comportamiento, mientras que quien hace algo por convención, el hecho de que exista ese comportamiento recurrente al que se refiere la primera cláusu-

23 Vid., al respecto, SEARLE, 1995, y AnsCOMBe, 1958: 22-25.

24 Puede verse el citado texto de LEWIS, 1969 (sus distintas definiciones de «convención», cada vez más sofisticadas, se encuentran en 42, 56 y 78). Prescindo aquí de la discusión concreta de estas cláusulas y de las posibles alternativas, como las de SEARLE (el cual habla de «hecho institucional»), o LAGERSPETZ (el cual habla de «creencia mutua» en vez de conocimiento común), etc. Tomo como modelo la definición de «convención» que aparece en el trabajo de M. NARVÁEZ. Cfr. NARVÁEZ, 2004: 312 y ss. 
la constituye una razón para realizar la conducta correspondiente. Es la llamada «condición de dependencia», acerca de cuyo alcance he de referirme en el apartado 6.5. Por último, la cuarta cláusula menciona la necesidad de que se dé conocimiento común entre los participantes, al que ya he aludido hace poco. Según LEWIS, se puede definir «conocimiento común» del siguiente modo: de ellos:

$p$ es conocimiento común entre los miembros de un grupo $G$ si y sólo si cada uno

1. Sabe que $p$.

2. Sabe que cada uno de los miembros de $G$ sabe que $p$.

3. Sabe que cada uno de los miembros de $G$ sabe que cada uno de los miembros de $G$ sabe que $p$; y así sucesivamente ${ }^{25}$.

La presencia de este conocimiento común en las convenciones es importante, sobre todo, porque supone la plasmación de la idea de expectativa de reciprocidad. Las creencias y actitudes que están presentes en quienes contribuyen a la generación de una convención consisten en su disposición a realizar $p$ con la condición de que los demás miembros de $G$ también lo hagan. Es por ello que puede afirmarse que la subsistencia de una convención depende de que varios individuos se conformen a una regularidad de comportamiento, porque se espera que también los demás se conformen y por la misma razón. Esto enlaza con una perspectiva propia de la interacción estratégica, según la cual el hecho convencional subsiste no sólo cuando cada miembro de $G$ realiza $p$ porque los demás miembros hacen lo mismo, sino que cada cual lo hace porque tiene expectativas fundadas de que los demás harán lo mismo y espera que eso suceda. Pero, además, se espera que los demás tengan también la expectativa de que todos harán lo mismo, y así sucesivamente.

Esta circunstancia pone de relieve que la subsistencia de una convención exige el carácter público de la misma (al menos en relación con los miembros de $G$ ). El comportamiento recurrente, pues, tiene que ser repetido por todos y a la vista de todos ${ }^{26}$.

\subsection{La creación de realidad social}

Así, pues, los hechos sociales, convencionales o no, conforman la realidad social. Puesto que los hechos sociales se constituyen a través de estados intencionales, se puede afirmar que la realidad social depende de estados intencionales. Ahora bien, esta afirmación puede resultar extraña a primera vista. ¿Cómo puede ser que la realidad esté constituida por estados intencionales? Si esto es así, ¿no se convierte tal realidad en subjetiva y, por tanto, en radicalmente inaprensible?

Contestando a la primera pregunta, hay que decir que una de las formas más comunes en la que los estados intencionales contribuyen a la creación de hechos sociales es a través de las llamadas reglas constitutivas, que obedecen a la fórmula acuñada por SEARLE: «X cuenta como Y en el contexto C». En qué medida esto es así respecto al

25 LEWIS, 1969: 52 y ss., y GILBERT, 1981: 87.

26 Celano, 1995: 41. 
Derecho y qué relación se da entre los hechos convencionales y las reglas constitutivas, es algo sobre lo que volveré más tarde ${ }^{27}$.

Respecto a la segunda pregunta, conviene distinguir cuidadosamente dos sentidos de la distinción entre objetivo y subjetivo. En sentido ontológico, la realidad natural sería objetiva (su existencia es independiente de estados intencionales), mientras que la realidad social sería subjetiva (su existencia es dependiente de estados intencionales). Pero esta distinta conformación de la realidad no impide que epistemológicamente ambas puedan ser conocidas de manera objetiva (donde «objetiva» aquí significa «sin implicación valorativa»).

En relación con este extremo, quisiera aclarar que nada de lo dicho prejuzga quién está en mejor posición para «conocer» el Derecho. Suele haber en este sentido una propensión, proveniente de visiones hermenéuticas, a considerar que quienes se hallan en esa posición epistémica privilegiada serían los participantes (en la terminología de HART, quienes sustentan el punto de vista interno). Pero esto no es necesariamente así. También es razonable pensar en una prioridad epistémica del observador. En efecto, podría decirse que el participante, a diferencia del observador, no es capaz de entender cabalmente el fenómeno del cual forma parte, ya que no es consciente de todas las piezas que hay que encajar para comprenderlo ${ }^{28}$.

\section{HECHOS CONVENCIONALES Y REGLA DE RECONOCIMIENTO}

De acuerdo con (TS), la existencia de ciertos hechos sociales sería, al menos, condición necesaria de la existencia de sistemas jurídicos. No todos los teóricos del Derecho coinciden a la hora de establecer qué tipo de hechos sociales son los relevantes. Por ejemplo, en una interpretación bastante extendida, algunos teóricos realistas defenderían (TS) no convencionalista. Tampoco Austin la defendería, tal como he dicho anteriormente. HART, sin embargo, sería el mejor representante de una tesis convencionalista. Según este autor, como sabemos, se requieren dos condiciones para que pueda decirse que un sistema jurídico existe:

(CE1): Que exista una regla de reconocimiento que permita conocer cuáles son los criterios de pertenencia de las otras reglas del sistema.

(CE2): Que las reglas identificadas a partir de la regla de reconocimiento se cumplan generalmente por el grueso de la población ${ }^{29}$.

27 SEARLE dice al respecto que mientras las convenciones son arbitrarias, las reglas constitutivas no lo son (al menos no lo son en el mismo sentido). Pone ejemplos relativos al ajedrez. Las reglas que definen los movimientos permitidos de las piezas son reglas constitutivas, sin ellas no existiría el ajedrez; en cambio, que el rey sea de mayor tamaño que el peón es convencional (podría ser al revés y ello no afectaría para nada al juego del ajedrez). Cfr. SEARLE, 1995: 46. Para un análisis algo distinto de la arbitrariedad en las convenciones, vid. MARMOR, 1996. Volveré sobre ello en el apartado 6.4.

28 Aunque este último enfoque tal vez no goce actualmente de demasiadas simpatías, no me parece que sea descartable sin más ( $c f r$., por ejemplo, OpalEK, 1971: 44). En todo caso, lo que indico en el texto es que la visión que defenderé respecto a las condiciones necesarias de existencia del Derecho es compatible con ambas perspectivas.

29 HART, 1961: 147. A decir verdad, HART se refiere en este punto a la existencia de todas las reglas secundarias y no sólo a la de la regla de reconocimiento. Ahora bien, si entendemos que las de adjudicación y las de 
Ambas condiciones parecen hacer referencia a tipos de hechos sociales distintos y pueden plantear problemáticas sólo parcialmente coincidentes. Mientras que en (CE1) los problemas girarían en torno a las condiciones de existencia de la regla de reconocimiento y parece que exigen la presencia de hechos convencionales, en (CE2) se alude a la llamada «eficacia» de las normas, y tal vez ésta pueda ser explicada aludiendo a hechos sociales no convencionales.

Ésta parece ser al menos la posición de HART cuando sostiene que, a diferencia de lo que ocurre con la existencia de las reglas sociales (entre ellas la regla de reconocimiento), a la hora de determinar la eficacia de las normas legisladas no se requiere la presencia del punto de vista interno. Sea como fuere, a continuación me ocuparé únicamente de la primera condición ${ }^{30}$.

En lo que sigue voy a entender la primera condición de existencia (CE1) de los sistemas jurídicos del siguiente modo:

(CE1): Para todo sistema jurídico existe una convención con una dimensión constitutiva, a partir de la cual se puede establecer una regla técnica, vinculada a una proposición anankástica social, cuya función es la de identificar de manera autónoma el Derecho positivo de una determinada comunidad.

Vayamos por pasos y analicemos el sentido y algunas implicaciones de los elementos que aparecen en (CE1): convención, dimensión constitutiva, regla técnica asociada a una proposición anankástica social, identificación y autonomía del Derecho.

\subsection{Convención}

Algunas de las afirmaciones que realiza HART respecto a la regla de reconocimiento son que ésta es una regla social y que existe como una cuestión de hecho. Esto puede interpretarse diciendo que la existencia de la regla de reconocimiento como regla social es un hecho convencional ${ }^{31}$.

Si esto es así, la verdad de la proposición expresada por el enunciado «En la sociedad S existe la regla de reconocimiento $\mathrm{R} \gg$ dependerá de la existencia de hechos convencionales. ¿Cuáles son esos hechos convencionales?

Como es sabido, HART entiende que la regla de reconocimiento existe como una práctica normalmente coincidente de los funcionarios y las personas privadas a la hora de identificar el Derecho de una determinada sociedad, cuyo contenido se manifiesta por el uso que esas personas realizan de determinados criterios de identifica-

cambio se identifican a partir de aquélla, bastará, en última instancia, con hacer referencia a sus condiciones de existencia para establecer las de un sistema jurídico.

${ }^{30}$ Debo insistir acerca de que el planteamiento de esas condiciones se hace con la vista puesta en toda teoría del Derecho y no sólo en las de corte positivista. Los autores no positivistas seguramente añadirán otras condiciones de existencia, pero, si estoy en lo cierto, no pueden omitir tomar en consideración CE1 y CE2.

31 Hay que matizar que HART sostiene su llamada «teoría práctica de las reglas» en un principio como una teoría general para dar cuenta de todas las reglas sociales. Sin embargo, en el Postscript a The Concept of Law, y después de las críticas recibidas por RAZ y DwORKIN, HART redimensionará el alcance de dicha teoría al circunscribirla a una subclase de reglas sociales, a las que llama «convenciones sociales», entre las que se encontraría la regla de reconocimiento ( $c f r$. HART, 1994: 256). 
ción $^{32}$. Ahora bien, el uso de criterios compartidos de identificación debe ir acompañado por una determinada actitud, que HART denomina «punto de vista interno». Las autoridades de una determinada sociedad, y entre ellas especialmente los jueces, se comportan de una manera que es consistente con el hecho de seguir la regla que permite identificar el Derecho válido de esa sociedad. Ello se refleja en un conjunto de compromisos normativos que aprueban la conducta convergente como justificada y que condenan las desviaciones. Ésta es la actitud crítico-reflexiva que HART denomina punto de vista interno.

El punto de vista interno puede ser traducido en términos de hechos convencionales, de tal modo que, partiendo de lo que dijimos al definir «hecho convencional», el enunciado «En la sociedad S existe la regla de reconocimiento R» podría analizar así:

1. La mayoría de los juristas de la sociedad $S$ usa los criterios $C 1, C 2 \ldots C n$ (que forman la regla de reconocimiento de $S$ ) cada vez que tiene que identificar el Derecho de $S$.

2. La mayoría de los juristas de $S$ cree que 1 .

3. La creencia de que se da 1 constituye una razón para usar esos criterios en esas circunstancias.

4. Hay un conocimiento común entre la mayoría de los juristas de lo que se dice en las anteriores cláusulas.

Respecto a 1 puede haber discusión sobre si el grupo relevante es el de los juristas en general o el de los jueces. El texto de HART, como ya apunté en el capítulo V, da lugar a interpretaciones diversas. En algunas ocasiones HART se refiere a acciones de identificación de autoridades («courts and officials») y de sujetos privados, mientras que en otras enfatiza el papel desempeñado por los Tribunales, casi en exclusiva.

Parece, de todos modos, que tiene sentido afirmar que los sujetos relevantes en estos casos serían todos aquellos que profesionalmente necesitan identificar el Derecho de una determinada sociedad (por tanto, no sólo jueces y demás autoridades, sino también abogados). Es difícilmente concebible el funcionamiento de una sociedad en la que hubiera una discrepancia generalizada entre el sector oficial y el «privado» a la hora de usar criterios de identificación del Derecho. Pero no me voy a ocupar más de esta cuestión.

Es preferible preguntarse ahora por qué es ventajoso este enfoque. Es decir, al margen de la interpretación que quepa dar a las palabras de HART, ¿qué razones justificarían el adoptar una versión convencionalista de la primera condición de existencia de los sistemas jurídicos?

Creo que existen al menos dos razones para ello ${ }^{33}$. En primer lugar, es un planteamiento necesario para evitar un regreso al infinito, y en segundo lugar, es la forma más adecuada de romper con un posible círculo vicioso. El primer problema ya fue abordado por HART de forma consciente, pero no así el segundo.

\footnotetext{
32 Cfr. HART, 1961: 134.

33 Existe una tercera razón: esta perspectiva posibilita concebir al Derecho como un sistema normativo autónomo. Pero el examen de esta justificación lo reservo para el apartado 5.4.
} 


\subsubsection{Un regreso finito}

Es común entender que en los sistemas jurídicos unas normas autorizan la creación de otras, y así sucesivamente. Este proceso debe, sin embargo, tener un final, so pena de caer en un regreso al infinito. Las propuestas de poner punto final a esta cadena normativa van, como sabemos, desde el soberano de AusTin, hasta la regla de reconocimiento de HART, pasando por la Grundnorm de KELSEN.

HART, sin embargo, es el que planteó más claramente la cuestión y dio en este sentido el paso decisivo para su resolución ${ }^{34}$. Como cierre del sistema se requiere una regla que confiera validez al resto de normas, pero de la cual no tenga sentido predicarla ${ }^{35}$. Esta regla es la regla de reconocimiento. Su existencia necesariamente es una cuestión de hecho ya que no puede ser derivada de otras normas del sistema. Pero, además, se trata de un hecho convencional, debido a la necesaria coordinación que debe darse a la hora de identificar el Derecho de una determinada sociedad: sin una práctica coordinada de identificación no existiría el Derecho como fenómeno social. Volveré sobre esta cuestión más adelante.

\subsubsection{Un círculo virtuoso}

El segundo problema es bien conocido. Expresado brevemente: si para saber cuál es el Derecho de una determinada sociedad se necesita una práctica de identificación concurrente de (al menos) los funcionarios de ese sistema y si para saber quién es funcionario de ese sistema se requiere haber identificado las reglas de cambio y de adjudicación a través de la regla de reconocimiento, entonces parece que se cae en un círculo vicioso. No podríamos saber quién es funcionario sin la presencia previa de una regla de reconocimiento, pero ésta no podría existir sin la conducta de los funcionarios.

Este inconveniente hay que afrontarlo tarde o temprano porque de su elucidación depende buena parte de las respuestas a otras cuestiones. Una de estas cuestiones es la que planteó PRIETO SANCHís en relación con uno de mis anteriores trabajos, a raíz del uso analógico que respecto a la existencia continuada del Derecho hice de la idea de SEARLE de la existencia continuada del dinero: en ambos casos se requeriría que la gente crea que algo es dinero o algo es Derecho y que actúe en consecuencia. Dice PRIETO al respecto: «... la analogía con el ejemplo de SEARLE sobre el dinero está bien traída. Ahora bien, los papeles (cada día más escasos) que uno lleva en la cartera, ¿dejarían de ser dinero el día en que todos dejásemos de creer en que eso es dinero, o más bien dejaríamos de creer que eso es dinero cuando dejara de funcionar como tal?; el Derecho y su regla de reconocimiento, ¿existen en virtud de una creencia, de manera que, desaparecida ésta, colapsaría el orden jurídico, o más bien creemos que es Derecho porque

34 Cfr. KELSEN, 1960: 202. La solución de KELSEN, según la cual la Grundnorm era una norma presupuesta, no es adecuada, por cuanto o bien genera un regreso al infinito de normas presupuestas, o bien introduce elementos de carácter sociológico, que hacen que la propuesta sea «impura» desde las propias coordenadas del autor.

35 Cfr. HART, 1961: 132. 
funciona como tal (acaso en virtud de una voluntad antes que de una creencia) y sólo abandonaríamos esa creencia si dejara de funcionar y perdiera toda eficacia?» ${ }^{36}$.

Como digo, afrontar esta cuestión y otras requiere abordar primero el problema de la circularidad. Lo haré a través de un ejemplo. Imaginemos que nos reunimos un grupo de filósofos del Derecho y constitucionalistas y redactamos una constitución, tomando como base la actualmente vigente en España. Introducimos en ella todos los «avances» que se nos puedan ocurrir dentro de nuestras respectivas materias: una lista muy completa de derechos humanos, una distribución modélica de competencias entre autonomías y gobierno central, la supresión de órganos difícilmente justificables, la eliminación de contradicciones, lagunas, etc. Es posible que el producto sea técnicamente muy superior a la Constitución de 1978. Ahora bien, resulta casi absurdo preguntarnos si esa constitución modélica pasaría a ser la constitución española actualmente vigente, ni aunque tuviéramos la pretensión de que lo fuera. Imaginemos, además, que todos los participantes utilizamos los mismos criterios para identificar esa constitución y pensamos que los demás utilizan éstos y no otros, entre otras razones porque los demás los utilizan, etc. En algún sentido, en este diseño hipotético puede existir una regla de reconocimiento que pretendiera identificar las reglas de adjudicación a través de las cuales se designarían a los jueces ${ }^{37}$, pero lo que no existe con total seguridad es la segunda condición necesaria de existencia de los sistemas jurídicos, la eficacia general de las normas identificadas a partir de la regla de reconocimiento, ya que por hipótesis el grueso de la población no las cumple ni hay jueces que sancionen el incumplimiento. Si esto es así, aunque a través de la regla de reconocimiento mencionada se pudieran identificar «autoridades», éstas lo serían de un sistema jurídico inexistente (por carecer de eficacia). ¿Qué nos muestra este ejemplo imaginario? ${ }^{38}$.

Para empezar, el ejemplo pone de relieve que el concepto de Derecho que normalmente nos interesa es aquel que nos permita identificar sistemas jurídicos existentes. Alguna razón puede haber para estudiar sistemas jurídicos inexistentes (ideales), pero éstos no suelen constituir el objeto de estudio prioritario de los juristas. Por otro lado, el ejemplo evidencia que resulta problemático hablar de «autoridades» (y de ahí las comillas), si los candidatos a serlo son permanentemente ineficaces. Es decir, parece que existe una vinculación conceptual entre el concepto de autoridad más adecuado al uso de los juristas y la eficacia de un sistema jurídico. Alguien a quien desobedecen sistemáticamente los miembros a los que van destinadas las normas que forman un determinado sistema jurídico (o aún más: ni siquiera toman esas normas en consideración) no parece ser un candidato idóneo a recibir el título de autoridad de ese sistema. Las anteriores observaciones tal vez permitan arrojar luz acerca del planteamiento que aquí defiendo.

Hay dos modos de romper el círculo vicioso del que estoy hablando. El primero trataría de desprenderse del carácter circular del argumento. Consistiría en suponer

36 Prieto Sanchís, 2008: 491. Vid. mi respuesta en Vilajosana, 2008.

37 Digo «en algún sentido» por cuanto incluso la existencia de la regla de reconocimiento podría ser puesta en cuestión, dado lo que afirmo en el texto en relación con quiénes son los sujetos relevantes para tener en cuenta sus acciones de identificación.

38 A quien el ejemplo le parezca demasiado irreal, sugiero que lo sustituya por el del conjunto de las normas que pueda dictar un gobierno en el exilio. 
que la autoridad jurídica no es dependiente de reglas. Ésta sería la idea sugerida por NINO, consistente en caracterizar a los órganos primarios no como aquellos que están autorizados a declarar prohibidos o permitidos los actos de coacción, sino como los que de hecho pueden determinar el ejercicio del monopolio coactivo estatal en casos particulares ${ }^{39}$. Esta primera opción, que también es la adoptada por PRIETO, presenta problemas de adaptación respecto a lo que se suele considerar «autoridad jurídica», al tiempo que no permite distinguir una autoridad jurídica de cualquiera que tenga un simple poder de $\left\langle f a c t o »{ }^{40}\right.$.

La segunda manera aceptaría la circularidad, pero trataría de desprenderse de su carácter vicioso. Consistiría en entender la autoridad jurídica en términos de hechos convencionales ${ }^{41}$. Así, un grupo de individuos guía su conducta a través de una cierta regla, es decir, toma la regla como dándole buenas razones para la acción. Si se da esa regla (y las reglas identificadas a través de ella son seguidas por el grueso de la población), un determinado sistema jurídico existe. Si un sistema jurídico existe, entonces esa regla que guía la conducta de nuestro inicial grupo de individuos es correctamente descrita como la regla de reconocimiento de ese sistema jurídico. Por tanto, aquellos individuos que guían su conducta a través de esa regla son propiamente entendidos como «autoridades». Son, en un sentido, autoridades en virtud de esa regla (o, mejor dicho, de reglas identificadas a través de esa regla), pero no son autoridades antes que ella (ni en sentido factual, ni lógico). Su conducta hace posible la existencia de la regla; pero es la regla la que los hace autoridades ${ }^{42}$. De este modo, con la introducción de actitudes y creencias recíprocas se elimina el carácter vicioso del círculo. Si se quiere, éstas sí que son circulares, pero no la teoría.

Aquí es donde cobra sentido la analogía con la existencia del dinero. En una determinada sociedad, algo (un objeto físico, una anotación contable, etc.) es dinero (es depositario de valor y es aceptado como instrumento de intercambio) sólo si el grueso de los miembros de esa sociedad creen que es dinero y actúan de acuerdo con esta creencia (es decir, lo toman como depositario de valor y lo utilizan habitualmente como instrumento de intercambio). Nótese que la existencia de la creencia compartida y la conducta correspondiente es una condición necesaria de la existencia del dinero, pero no tiene por qué ser suficiente. Puede establecerse una condición adicional, como puede ser que lo expida un banco o cualquier otra. Pero lo que hay que destacar ahora es que al tratarse de una condición necesaria de la existencia del dinero, de no darse aquélla, éste no existe.

Así es como veo yo, mutatis mutandis, la existencia del Derecho en una determinada sociedad: la existencia de una regla de reconocimiento, interpretada del modo que aquí se ha hecho, es una condición necesaria de la existencia de un sistema jurídico en esa sociedad. De lo cual se sigue que si no se da la convergencia de creencias, actitudes

39 NiNO, 1982: 60.

40 Cfr. para esta crítica RuIz Manero, 1990: 130-132.

41 Por ejemplo, en la línea sugerida por E. LAgERSPETz (1995: 159 y ss.).

42 Así se expresa en ColEMAN, 2001: 101. Y, en parecidos términos, se pronuncia S. SHAPIRO en SHAPIRO, 2001: 149-191. Me temo, sin embargo, que SHAPIRO ya no estaría de acuerdo con lo que afirmo en el texto, a tenor de lo que sostiene en su último libro, que está a punto de publicar, y cuyo manuscrito he podido consultar gracias a su gentileza. 
y comportamientos que conlleva la identificación de las normas de ese sistema a través de los mismos criterios, no puede hablarse de que un determinado sistema jurídico existe. Ahora bien, ésta es únicamente una condición necesaria. Se requiere al menos otra, que es la eficacia de las normas identificadas a través de los criterios que forman aquella regla.

Después del rodeo que he dado, estamos en condiciones de tratar la interesante cuestión planteada por PRIETO acerca de si las creencias son anteriores o posteriores al funcionamiento efectivo del sistema. Para ello recordemos que los comportamientos relevantes para predicar la existencia de un sistema jurídico son de dos tipos, según se refieran a la primera condición (la existencia de la regla de reconocimiento) o a la segunda (la eficacia de las normas). Al menos en relación con la primera condición, no es comprensible entender los comportamientos separados de las creencias mutuas. Debido a esa razón, si se acepta lo que aquí sostengo, no resulta inteligible plantear la cuestión en términos de si las creencias preceden a los comportamientos, o viceversa. Veamos por qué.

En primer lugar, hallamos las acciones consecuentes con las creencias y actitudes acerca de los criterios de identificación de las normas del sistema usados comúnmente por quienes se dedican profesionalmente a la identificación del Derecho. En concreto: la invocación por parte de los abogados en los tribunales de ciertas normas en cuanto que éstas son identificadas usando determinados criterios (que solemos equiparar a las fuentes del Derecho, por decirlo brevemente); el uso de esos mismos criterios por parte de los órganos administrativos y de los tribunales a la hora de dictar sus resoluciones; el uso de esos mismos criterios de identificación entre los practicantes de la dogmática jurídica en el momento de sistematizar y analizar las normas jurídicas que someterán a estudio.

Este primer tipo de actos tiene la particularidad de constituir hechos convencionales en la terminología que he empleado anteriormente. El sentido de estos comportamientos no puede ser aprehendido sin hacer referencia a las creencias de quienes lo llevan a cabo. Además, tales creencias no son independientes entre sí, sino que se hallan relacionadas, como muestra el concepto de conocimiento mutuo. El concepto de hecho convencional intenta capturar esta idea. Los hechos convencionales serían un subtipo de hechos sociales caracterizados por la presencia de ciertos rasgos, a los que ya me referí, entre los que destaca la presencia de conocimiento mutuo.

En este sentido, al igual que sucede con el dinero, sólo podrá ser considerado Derecho de una determinada sociedad lo que ciertos agentes identifiquen como Derecho de esa sociedad. ¿No será esto después de todo también circular? Sí, pero resulta explicativo, por cuanto muestra la dimensión constitutiva de la regla de reconocimiento ${ }^{43}$.

Del mismo modo que unos determinados trozos de papel pueden dejar de ser dinero en una sociedad en el momento en que sus usuarios dejen de creer que lo son y actúen en consecuencia (dejen de otorgarles valor y no los acepten como instrumento de intercambio, por ejemplo debido a un fenómeno de hiperinflación) y ello aunque los haya puesto en circulación el organismo competente y los avale el Estado, igualmente unas

${ }^{43}$ Nada de extraño hay en hablar de fenómenos circulares (reflexivos). Los científicos hace tiempo que identificaron las relaciones causales bicondicionales o procesos de retroalimentación. 
normas o el sistema jurídico en su conjunto pueden dejar de ser Derecho en una determinada comunidad si los juristas en general dejan de creer que lo son y actúan en consecuencia (es decir, no se dan las cláusulas citadas y los comportamientos consecuentes con las mismas). Y esto será así, por ejemplo en el caso español, con independencia de lo que diga el Código Civil respecto a las fuentes del Derecho. Creo que esto es lo que quiere sugerir HART cuando afirma que la existencia de la regla de reconocimiento es una cuestión de hecho ${ }^{44}$. En caso de discrepancia entre lo que diga la disposición de una ley (si es que existe) en la que se establezcan formalmente las fuentes del Derecho de un sistema jurídico, por un lado, y las creencias, actitudes y comportamientos de los juristas relativos al uso de los criterios de identificación que forman la regla de reconocimiento, por otro, lo que hay que tomar en cuenta a los efectos que ahora interesa es esto último sencillamente porque tales creencias, actitudes y comportamientos (que son las condiciones de existencia de esa regla de reconocimiento) son constitutivos del Derecho de la comunidad de que se trate.

En segundo lugar, además de los comportamientos que son condiciones de existencia de una regla de reconocimiento, la existencia de un sistema jurídico en una determinada sociedad requiere la presencia de otro tipo de actos, que dan cuenta de la eficacia de las normas. Éstos pueden ser, en resumidas cuentas, actos de cumplimiento de las normas del sistema por parte de sus destinatarios y actos de los tribunales sancionando los incumplimientos que se den. Como ya he dicho, estos actos conforman obviamente hechos sociales, pero tal vez no tienen por qué ser convencionales.

\subsection{La dimensión constitutiva de las convenciones}

La crítica central que HART dedica al trabajo de AUSTIN es que éste ofrece una imagen distorsionada del Derecho, puesto que la explicación del fenómeno jurídico basada exclusivamente en hábitos de comportamiento deja fuera el elemento normativo propio de aquél. Con la introducción de la regla de reconocimiento como convención se pretende superar estos inconvenientes de la posición austiniana. Ahora bien, el desafío consiste entonces en mostrar de qué modo una práctica social puede «generar» normas sin caer por otro lado en el iusnaturalismo.

Una forma prometedora de abordar esta cuestión puede partir del mencionado trabajo de D. LEWIS ${ }^{45}$. Según este autor, un típico problema de coordinación se da cuando varios agentes tienen una estructura particular de preferencias respecto a sus modelos de conducta respectivos. Esto significa que entre las diversas alternativas que se les presenta en un conjunto dado de circunstancias, cada uno tiene una preferencia más fuerte para actuar como lo harán los demás agentes, que su propia preferencia para actuar de una determinada manera. La mayoría de los problemas de coordinación se solventa fácilmente a través de simples acuerdos entre los agentes de actuar según una alternativa elegida arbitrariamente, de tal manera que se asegure la uniformidad de

${ }_{44}$ No quiero afirmar rotundamente que sea ésta la idea que tenga HART en mente. En realidad, como ha sido puesto de relieve en alguna ocasión, el concepto de hecho manejado por este autor no es del todo claro. Cfr. JACKSON, 1988.

45 Cfr. LEWIS, 1969. 
acción entre ellos. Sin embargo, cuando un problema de coordinación es recurrente y el acuerdo es difícil de obtener (por ejemplo, porque el número de agentes es considerablemente alto), es muy probable que surja una convención.

Entre las ventajas que presenta este planteamiento podemos destacar dos ${ }^{46}$. Primero, rescata y precisa la intuición de que las convenciones, en algún sentido, son arbitrarias: si una regla es una convención, debe haber al menos alguna alternativa que los agentes hubieran podido escoger. Segundo, ofrece una respuesta a la pregunta sobre la normatividad propia de las convenciones: las razones para seguir una regla que es una convención están fuertemente unidas al hecho de que otros también la siguen. No tendría sentido seguir una regla convencional si no es realmente practicada por la comunidad pertinente, ya que no serviría para resolver el problema de coordinación que está en su base.

Llegados a este punto, ¿puede afirmarse que es transportable sin más el concepto de convención de LEWIS a la regla de reconocimiento, cuya existencia es condición necesaria de la existencia de un sistema jurídico ${ }^{47}$ ?

$\mathrm{Al}$ respecto, quizás quepa poner en duda que la estructura típica de la regla de reconocimiento responda a la que está pensando LEWIS. Por un lado, es demasiado exigente el requerir que exista un conjunto de preferencias estructuradas ex ante de una determinada manera. Es decir, parece irreal pensar que cada juez tendría su propia preferencia (a la hora de considerar criterios de validez jurídica), pero todos tendrían una preferencia dominante de actuar como es previsible que lo hagan los demás ${ }^{48}$. Esta idea, pues, puede ser abandonada, sin que ello suponga rechazar el papel reservado a los hechos convencionales, tal como los he tratado.

Por otro lado, quizás resulte poco exigente como modelo de una práctica normativa autónoma como es el Derecho. En este punto, resulta útil concentrar nuestra atención en la dimensión constitutiva de las convenciones ${ }^{49}$.

En teoría del Derecho es común distinguir dos tipos de reglas: regulativas y constitutivas. Estas últimas, como ya dije antes, tienen la virtud de contribuir a la «creación» de la realidad social y obedecen a la fórmula canónica «X cuenta como $\mathrm{Y}$ en el contexto $\mathrm{C} \gg$. Aunque el problema de la normatividad de la regla de reconocimiento suele ser abordado desde la perspectiva de considerar tal regla como una regla regulativa ${ }^{50}$, no

46 En el sentido expresado por A. MARmor, al que sigo en este punto. Cfr. MARMor, 2001a: 200.

47 Uno de los primeros en intentarlo fue Postema. Cfr. Postema, 1982: 165-203.

48 En este mismo sentido, vid. ColEmAn, 2001, 95. Es de destacar que este autor ha modificado en este punto su posición, puesto que en anteriores trabajos se había alineado, junto a PosTEMA, en la traslación más mimética del esquema de LEWIS al problema que aquí nos ocupa.

49 MARMOR ha propuesto lo que llama «convenciones constitutivas» contrapuestas a «convenciones de coordinación» (cuyo modelo sería el de LEWIS: $c f r$. MARMOR, 1996). Sin embargo, como ya he dicho en otro trabajo (Vilajosana, 2003), me parece que esta dicotomía no se puede plantear en términos excluyentes, puesto que pueden darse convenciones constitutivas, destinadas a resolver problemas de coordinación (como es el caso que expongo en el texto). Dado que el planteamiento que defiendo, pues, difiere en este punto del que realiza este autor, prefiero, para evitar equívocos, hablar de «dimensión constitutiva de las convenciones» (que podrían ser de coordinación) más que de «convenciones constitutivas», en el sentido de MARMOR (que implicaría que excluyen el problema de coordinación). Sobre el planteamiento de MARMOR, $c f r$. TUZET, 2007.

${ }_{50} \mathrm{Y}$ a ello dio pie el propio HART al considerar que la regla de reconocimiento, a pesar de ser una regla secundaria, impone obligaciones. Vid., al respecto, la polémica que han mantenido RUIZ MANERO y BuLYGIN en la revista Doxa. Cfr. BuLYgin, 1991; Ruiz MANERO, 1991. 
es descabellado pensar que la regla de reconocimiento es una convención constitutiva en este sentido. Así, del mismo modo que lo que cuenta como dinero en una sociedad es lo que sus miembros creen que es dinero, lo que cuenta como Derecho en una determinada sociedad proviene del uso de determinados criterios de identificación del Derecho de esa sociedad por parte de los juristas y de las diversas creencias y expectativas generadas.

Si se procede de este modo, queda más claro dónde reside el factor de autonomía del Derecho como fenómeno social y uno de los sentidos de su normatividad. Ambas circunstancias tienen que ver con el carácter convencional de las prácticas jurídicas.

Cada juez puede utilizar los criterios mencionados por razones muy distintas (morales, estratégicas, etc.), pero todos deben coincidir en utilizar éstos y no otros porque los demás también utilizan éstos y no otros. Este punto es importante, por lo que debe quedar claro. Por supuesto que cada regla de reconocimiento refleja las concretas circunstancias y convicciones políticas de la sociedad de la que se trate y del momento en que se trate. Ahora bien, esto no es lo relevante en esta sede. Lo relevante es preguntarse si esas mismas convicciones por sí solas proporcionan las razones suficientes para actuar de acuerdo con la regla, aun si la regla en cuestión no es seguida por los demás. La respuesta de alguien que sostenga la Tesis convencionalista debe ser negativa ${ }^{51}$.

\subsection{Proposición anankástica social y regla técnica de identificación}

Si aceptamos que la existencia de una determinada regla de reconocimiento es un hecho convencional y como tal tiene una dimensión constitutiva, podemos concluir que con ella se crea una realidad social. Sin esa convención, no existirían criterios de identificación del Derecho de una determinada sociedad (y, por extensión, no existiría el Derecho como práctica normativa autónoma). Pero si esto es así, entonces puede decirse que un enunciado del tipo «En la sociedad $S$, utilizar los criterios $C 1, C 2 \ldots C n$ es condición necesaria para identificar el sistema jurídico de $S \gg$ expresaría una proposición anankástica, cuyas condiciones de verdad serían las mismas condiciones de existencia de la regla de reconocimiento de $S$ y que mencioné anteriormente ${ }^{52}$.

Hay que puntualizar que VON WRIGHT utiliza la idea de proposición anankástica para referirse a la realidad natural ${ }^{53}$, pero creo que no hay mayor inconveniente en sostener que, si se admite que puede hablarse de una realidad social tal como ha sido aquí tratada, también sobre ella se puede establecer dicho tipo de proposiciones, que podríamos llamar «proposiciones anankásticas sociales»: su verdad vendría dada en estos casos por la presencia de hechos sociales.

Si se admite este planteamiento, entonces es posible construir en base a tales proposiciones las correspondientes reglas técnicas, cuya formulación canónica podría ser: «Si se quiere identificar el sistema jurídico de $S$, utilícense los criterios $C 1, C 2 \ldots C n »$.

\footnotetext{
${ }^{51}$ Recuérdese el contrafáctico que se halla tras toda convención y que mencioné al comienzo de este trabajo.

52 En la misma línea, vid. NARVÁEZ, 2004.

53 Cfr. Von Wright, 1963: 29 y 118.
} 
Sólo si la proposición anankástica es verdadera, la regla técnica es útil (es decir, se consigue identificar el Derecho de una determinada sociedad).

De este modo se puede dar cuenta de algunas perplejidades que apunta, por ejemplo, COLEMAN. Este autor sostiene que decir que la regla de reconocimiento establece los criterios de legalidad es ambiguo, ya que puede significar simplemente que la regla marca algunas normas como Derecho válido y de este modo torna al Derecho determinado, o bien que además de eso, la regla juega el papel de posibilitar a los individuos que puedan identificar qué normas forman el Derecho de una comunidad, de tal modo que el Derecho se hace determinable. Lo primero sería una función ontológica de la regla de reconocimiento, mientras que lo segundo sería una función epistémica.

Creo que es pertinente la distinción, pero no veo qué se gana atribuyendo dos funciones distintas a la regla de reconocimiento. En cambio, si tratamos el tema como hemos hecho antes, vemos claramente separadas las cuestiones: una cosa es la realidad social constituida a partir de la regla de reconocimiento (ésta sería la cuestión «ontológica»), que permite conocer las condiciones de verdad de una proposición anankástica (que hace al Derecho «determinado»), y otra la regla técnica que a partir de ésta puede establecerse (lo que supone una cuestión «epistémica» y hace al Derecho «determinable»). Quien quiera identificar el Derecho de una determinada sociedad, no tiene más remedio que observar cuáles son los criterios de identificación que los propios miembros de la sociedad utilizan y proceder en consecuencia ${ }^{54}$.

\subsection{Identificación y autonomía del Derecho}

Hemos visto hasta aquí varias cuestiones relativas a las condiciones de existencia de una regla de reconocimiento, tales como el papel que en ellas desempeña el recurso al conocimiento común o el modo en que las prácticas de identificación del Derecho de una determinada sociedad contribuye a la constitución autónoma del fenómeno jurídico.

Para finalizar quisiera decir algo sobre una pretendida polémica acerca de la mejor explicación de las reglas de reconocimiento. Algunos autores enfatizan el aspecto funcional ${ }^{55}$, ya que suelen insistir en que las reglas de reconocimiento se caracterizan precisamente por tener la función de determinar los criterios de pertenencia de las normas a un determinado sistema jurídico. Estos autores subrayan el elemento de coordinación al que ya aludí. Por otro lado, están los que opinan que lo determinante a la hora de explicar tal tipo de reglas es la historia, ya que es ésta, y no la función de coordinación, la que determina cuál es la regla de reconocimiento de la sociedad en cuestión ${ }^{56}$.

Como suele suceder en muchas ocasiones, la disputa es estéril, ya que en realidad no discuten sobre lo mismo. Quienes consideran que no hay problema de coordinación que explique las distintas reglas de reconocimiento que existen en diferentes

${ }^{54}$ Sobre la función ontológica ya hemos dicho bastante en el texto; sobre la epistémica, vid. LeITER, 2001: 360 .

55 Por ejemplo, SHAPIRO, 2001: 158 y ss.

56 Por ejemplo, MARMOR, 2001a: 213. 
sociedades olvidan que efectivamente sí que existe un problema de coordinación y siempre el mismo en todos los casos. El problema de coordinación que resuelve la regla de reconocimiento es el de constituir un conjunto de criterios a partir de los cuales podamos saber cuál es el Derecho de una determinada sociedad. Sin esos criterios, no existiría el Derecho como fenómeno social en una determinada sociedad, ni podríamos identificarlo. Ahora bien, determinar cuáles sean en cada caso esos criterios se trata, por descontado, de una cuestión que atañe a la historia institucional de esa sociedad. Todos los sistemas jurídicos requieren criterios compartidos de identificación, pero no todos tienen por qué admitir como criterio, por ejemplo, la doctrina del precedente. Admitir este concreto criterio o no dependerá de la historia.

Se pone de relieve de este modo una ambigüedad de mayor calado que afecta al concepto de autonomía y que suele pasar desapercibida en los diversos tratamientos sobre esta cuestión. Está claro que la propiedad de ser autónomo es relacional. Un sujeto u objeto es autónomo respecto a algo o a alguien. En el asunto que nos ocupa, andan en juego dos posibles candidatos a ser la otra parte de la relación de autonomía del Derecho. Por un lado, la autonomía del Derecho se predica respecto a otros órdenes normativos (moral crítica, moral positiva), para lo cual resulta relevante la función de coordinación y la dimensión constitutiva que toda regla de reconocimiento tiene: sin ella (y sin la eficacia general de las normas del sistema, no lo olvidemos) no existe el fenómeno social llamado Derecho. Por otro lado, en cambio, la autonomía de un determinado sistema jurídico se predica en relación con otro sistema jurídico (ambos con sus respectivas reglas de reconocimiento), para lo que es relevante la historia institucional y los valores políticos imperantes en cada uno de ellos ${ }^{57}$.

\section{CINCO POSIBLES OBJECIONES}

Las teorías convencionalistas, en general, y las que conciben la regla de reconocimiento como una convención, en particular, han sido objeto de diversas críticas. Puesto que de ser exitosas, tales críticas podrían afectar negativamente a la versión convencionalista de la regla de reconocimiento que aquí he ofrecido, resulta oportuno terminar este capítulo con su examen. A continuación me ocuparé de las que me parecen las más destacadas: a) las que afectan a la normatividad de la regla de reconocimiento; $b$ ) las relativas al posible efecto que tiene la presencia de principios jurídicos en la existencia de la regla de reconocimiento; c) las que aluden a la repercusión que puede tener en dicha existencia el que haya discrepancias entre los juristas a la hora de identificar el Derecho de una sociedad; $d$ ) las que tienen que ver con el carácter arbitrario que se predica de las convenciones, y e) las que tildan de banales a las tesis convencionalistas.

Espero mostrar con este análisis que ninguna de estas posiciones consigue el fin que se propone.

57 Este último es un problema de identidad de un orden estatal desde una perspectiva sincrónica, del que me he ocupado en alguna ocasión ( $c f r$. VILAJOSANA, 1996). 


\subsection{La normatividad de la regla de reconocimiento}

Respecto al problema de la normatividad de la regla de reconocimiento, es conveniente empezar por hacer una distinción que evitaría muchos malentendidos. Una cosa es la normatividad predicada de la regla de reconocimiento y otra cosa distinta es preguntarse acerca de la normatividad del Derecho en su conjunto o del proceso de aplicación del Derecho entendido como práctica social. Además, hay otra forma de enfocar la normatividad del Derecho, que suele confundirse con alguna de las anteriores, y que tiene que ver con la pregunta acerca de si el Derecho obliga a los jueces. Conviene aclarar que en este trabajo interesa únicamente la normatividad propia de la regla de reconocimiento.

En este caso, hay que elucidar en qué sentido, si es que lo tiene, la práctica de identificación del Derecho de una determinada comunidad debe ser considerada obligatoria para quienes realizan dicha tarea. Es importante destacar que de lo que se trata ahora es de centrarnos en esa concreta tarea de identificación, es decir, en el uso compartido de determinados criterios para saber cuál es el Derecho de una sociedad determinada y no en otros problemas como el de la justificación del deber de obediencia al Derecho o el de la justificación de las sanciones institucionalizadas. Pues bien, entendido de este modo el problema de la normatividad de la regla de reconocimiento, entonces hay que ver cuáles son las opciones de respuesta.

Muchas veces, al hablar de normatividad de prácticas se toma como una alternativa exhaustiva y mutuamente excluyente la que considera que o bien no existe normatividad, es decir, la práctica en cuestión no es en ningún sentido comprensible de obligado cumplimiento, o bien lo es, y entonces esa obligatoriedad sólo puede ser de carácter moral. En ocasiones, se ha interpretado el punto de vista interno de HART según esta segunda opción y no seré yo quien niegue que algún texto del mismo pueda dar pie a esta exégesis ${ }^{58}$.

Sin embargo, en mi opinión, aunque las opciones citadas son obviamente excluyentes, en cambio no son conjuntamente exhaustivas. Existe la posibilidad de hablar de normatividad en el sentido en que se habla justamente de normatividad de las convenciones ${ }^{59}$. Ese elemento normativo presente en las convenciones consiste en lo siguiente: involucrarse en una práctica convencional supone realizar determinadas acciones al menos por la razón de que los demás también lo hacen ${ }^{60}$. Esto puede sonar extraño, pero sólo lo es si se confunden los problemas que aquí he distinguido, es de-

58 Es lo que hacen, por ejemplo, MACCORMICK y WEINBERGER, 1986: 132-133, y GARZÓN, 1993.

59 No afirmo que sea este sentido de normatividad el que los autores convencionalistas han defendido al hablar del carácter normativo de las convenciones. En realidad, no resulta nada claro decir, como sostienen muchos de estos autores, que de las prácticas de identificación de un sistema jurídico surge la obligación de identificar de esa manera al sistema jurídico en cuestión. Lo que sostengo es que la única forma plausible de considerar normativa dicha práctica (donde «normativo» significa simplemente «tener una razón para actuar») es la expresada en el texto. Si alguien considera que una razón de este tipo no tiene carácter normativo, entonces no tengo mayor problema en reconocer que no hay nada normativo en la práctica de identificación del Derecho de una determinada comunidad. Sobre las críticas a los intentos de establecer el carácter obligatorio de las convenciones, $c f r$. GREEN, 1988: 117-121; CELANO, 1995; MARMOR, 2001b: 28-29.

${ }^{60}$ Cfr. LEWIS, 1969. Si este elemento no se diera, no se resolvería el problema de coordinación que está en la base de toda convención. 
cir, si se toma esta idea como una respuesta al problema de la justificación del Derecho. En efecto, esta respuesta sería absurda como contestación al problema del deber de obediencia al Derecho, ya que este problema requiere inevitablemente una respuesta que se halla en el ámbito moral ${ }^{61}$. Sin embargo, si acotamos convenientemente la cuestión y nos preguntamos acerca de las razones por las cuales unos sujetos deberían usar unos determinados criterios y no otros para identificar el Derecho de una sociedad, entonces no tiene por qué considerarse desatinado que una razón sea la de que los demás también los usan. Es la misma razón que tenemos para seguir cualquier convención. Quede claro que ésa no tiene por qué ser la única razón. Pero ésta debe darse para que exista la regla de reconocimiento como convención de acuerdo con la cláusula tercera del esquema anteriormente citado.

Cuando existe esta regla y las normas identificadas a través de ella son eficaces, entonces existe un determinado sistema jurídico, con normas que seguramente impondrán determinadas obligaciones jurídicas a los jueces (me parece obvio que antes de la existencia de un sistema jurídico no pueden existir obligaciones jurídicas).

Una vez llegados a este punto entra en juego el último problema citado que tiene que ver con la normatividad y que no hay que confundir con los anteriores. Se suele formular con esta pregunta notoriamente ambigua: ¿tienen los jueces la obligación de cumplir con las normas jurídicas? En caso afirmativo, ¿de qué tipo de obligación se trata? Como acabo de decir, éste es un problema que sólo cabe abordar una vez que se han materializado las condiciones de existencia de un determinado sistema jurídico. Cuando esto es así, el propio sistema establecerá una norma de carácter obligatorio o bien una norma constitutiva de la que se puede inferir una regla técnica que nos indicará las condiciones para que alguien sea considerado juez en relación con ese sistema. Por ejemplo, podría interpretarse que esta última posibilidad es la que acoge nuestro sistema jurídico, a través de la Ley Orgánica del Poder Judicial, cuando establece que uno de los requisitos para acceder a la judicatura es la de jurar o prometer cumplir y hacer cumplir la Constitución y el resto del ordenamiento jurídico. Lógicamente, puede suceder que alguien no quede satisfecho con esta respuesta y desee seguir indagando acerca de por qué hay que cumplir las promesas. Cuando se hace esto, se pide una respuesta que sólo puede ser moral, por la simple razón de que solemos definir a las razones morales como últimas. No cabe sorprenderse, pues, que las últimas razones sean morales, puesto que del modo en que éstas suelen entenderse o bien hay razones de otro tipo, pero entonces no son últimas o bien son razones morales. Pero todo esto nada tiene que ver con las condiciones que hacen posible la existencia del Derecho.

\subsection{Convenciones y principios}

DwORKIN opina que en la práctica judicial podemos hallar diversas consideraciones que a los jueces les parecen relevantes para decidir los casos que se les presentan, razón por la cual no existe ninguna regla de reconocimiento que valide todas las razones, morales y no morales, que son relevantes a la hora de tomar decisiones judiciales ${ }^{62}$.

${ }^{61}$ Cfr. Villajosana, 2007, capítulo IV.

62 Para las críticas esbozadas en este apartado y en el siguiente, vid. DwORKIn, 1977 y 1986. 
La tesis de Dworkin en este punto, podría resumirse de este modo. El Derecho de un determinado país contiene, además de reglas, principios. Los principios no se identifican sólo por su origen, sino también por su contenido. Pero el contenido de los principios tiene forzosamente un componente moral. Por tanto, si queremos identificar el Derecho de un determinado país necesariamente deberemos hacer referencia a cuestiones morales, al menos a aquellas necesarias para identificar a los principios.

Pero ¿cuál sería el criterio de existencia de un principio jurídico si no podemos relacionarlo simplemente con su origen, con actos de creación? Según DwORKIN, un principio jurídico existe si se sigue de la mejor interpretación política y moral de las decisiones legislativas y judiciales pasadas en el ámbito de que se trate. Los principios jurídicos, pues, ocuparían un espacio intermedio entre las reglas jurídicas y los principios morales.

Las reglas jurídicas son creadas por las instituciones pertinentes y su validez deriva del origen, es decir, de la fuente del Derecho de que se trate (la legislación, la costumbre, etc.). Los principios morales son lo que son puramente por su contenido, y su validez está también relacionada únicamente con su contenido. Los principios jurídicos, por su parte, obtendrían su validez de una combinación de consideraciones basadas en fuentes y otras basadas en el contenido. Esta visión la generaliza DwORKIN llamándola «Derecho como integridad» y la describe así:

«De acuerdo con el Derecho como integridad, los enunciados jurídicos son verdaderos y aparecen en, o se siguen de, principios de justicia, equidad y principios procesales como el proceso debido, que ofrecen la mejor interpretación constructiva de la práctica jurídica de la comunidad» ${ }^{63}$.

La validez de un principio jurídico deriva, entonces, de una combinación de hechos y consideraciones morales. Los hechos relevantes son los relativos a las decisiones jurídicas (tanto de legisladores como de jueces) llevadas a cabo en el pasado dentro del ámbito correspondiente. Las consideraciones morales y políticas tienen que ver con las formas en que aquellas decisiones pasadas pueden ser mejor justificadas por los principios moralmente correctos (es decir, los correspondientes a la moral crítica).

Ahora bien, recuérdese que la regla de reconocimiento como regla social juega un papel decisivo no sólo para identificar el Derecho, sino para establecer su autonomía frente a otros órdenes normativos, que también se dan en una misma sociedad, como podrían ser la moral social o los usos sociales. La dificultad de establecer esta distinción estriba en que todos ellos son fenómenos normativos que se originan en prácticas sociales. El concepto de regla de reconocimiento ofrece un intento de establecer esta distinción, otorgando a la conducta e intenciones de un determinando conjunto de personas un papel decisivo en la constitución de la práctica jurídica.

Por su lado, el esquema de DwORKIN reside en última instancia en la práctica jurídica de una determinada sociedad. Pero el carácter jurídico de esa práctica es dado por descontado en el planteamiento de este autor. Recordemos que, para el Derecho como integridad, los enunciados jurídicos son verdaderos y aparecen en, o se siguen de, principios de justicia, equidad y principios procesales como el proceso debido, que

${ }^{63}$ R. DwORKIN, 1986: 225. 
ofrecen la mejor interpretación constructiva de la práctica jurídica de la comunidad. ¿Pero cómo identifica DwORKIN esas prácticas jurídicas de entre todas las prácticas sociales que se dan en una determinada comunidad? Pueden pensarse dos posibilidades. En ambas, tenemos que partir de una premisa indudable: si una práctica es jurídica, entonces alguna relación tendrá con el Derecho de esa comunidad. Una posibilidad sería aplicar la definición de Derecho que el propio DwOrKIN da. Pero si hacemos esto, el argumento se vuelve circular. Para saber cuándo una práctica es jurídica debemos acudir a los elementos que nos permiten identificar el Derecho de una determinada sociedad. Pero resulta que entre estos elementos se halla la referencia a la práctica jurídica que teníamos que identificar. La otra posibilidad es hallar criterios independientes para saber cuándo una práctica es jurídica. Pero esto es justamente lo que proporciona la regla de reconocimiento a la que DwORKIN no quiere acudir.

Tal vez las deficiencias que detecto en las tesis dworkinianas y las virtudes del esquema que defiendo quedarán más claras con un ejemplo. Imaginemos que alguien desea identificar el contenido del Derecho romano en un determinado periodo histórico (por ejemplo, el relativo a la época del emperador Augusto). La pregunta es: ¿qué pasos debe seguir? Más aún: ¿qué pasos siguen todos los romanistas cuando proceden a tal identificación? ¿Acaso toman como referencia un Derecho parecido a la mejor interpretación posible de las instituciones romanas, teniendo en cuenta los principios de justicia relativos a la moral crítica? Me parece que no. Lo que hacen es intentar comprobar, a través de los procedimientos empíricos pertinentes, cuáles eran los criterios que los propios usuarios del Derecho de la época en cuestión usaban para identificarlo (y cerciorarse de que el sistema en su conjunto era eficaz). Por tanto, frente a la disyuntiva entre identificar el Derecho tomando en cuenta los criterios de identificación efectivamente usados por (al menos) los funcionarios de un sistema jurídico e identificarlo a partir de la interpretación de instituciones jurídicas (¿cómo sabríamos que lo son?) bajo su mejor luz, parece que es más razonable hacer lo que hacen todos los romanistas. Pero si esto es así para el caso de la identificación del Derecho romano, ¿por qué debería ser distinto a la hora de identificar el Derecho de cualquier otro periodo histórico y de cualquier latitud?

\subsection{Convención y desacuerdos}

Según DwORKIN, existiría una profunda controversia entre juristas y entre jueces acerca de cómo habría que decidir jurídicamente determinados casos. La presencia de esta controversia llevaría a la conclusión de que el Derecho no puede residir en un consenso oficial como el que parece seguirse de la existencia de una regla de reconocimiento.

$\mathrm{Al}$ respecto podríamos hacernos dos preguntas: ¿existe de hecho esta controversia generalizada? En caso de que existiera, ¿es del tipo necesario para poner en cuestión la existencia de una regla de reconocimiento como regla social? No es descabellado responder negativamente a ambos interrogantes.

Respecto a la primera pregunta, resulta indudable que existen controversias entre juristas, en general, y entre jueces en particular, acerca de cómo decidir los casos judi- 
ciales. El hecho mismo de que existan procedimientos judiciales en los que al menos dos partes pueden aportar argumentos en favor de sus respectivas posiciones, y ambas pueden con sentido invocar razones jurídicas para que el fallo les sea propicio, es un indicador de que esa controversia es indisociable de la práctica jurídica.

Ahora bien, ¿hasta dónde llega esta controversia? ¿Puede decirse sin más que la presencia de estas disputas respecto a los casos judiciales suponen que todo el Derecho es controvertido? ¿Qué sucede con la multitud de decisiones jurídicas que se toman al margen del procedimiento judicial, como son los contratos que no se impugnan, las leyes que se cumplen, etc.? Seguramente, los casos que se podrían plantear en los tribunales y que en cambio no se plantean son muchísimos más que los que llegan a ellos.

Por lo que hace a la segunda cuestión, hay que recordar que no toda controversia que se produce en sede judicial es relevante para poner en cuestión la existencia de una regla de reconocimiento. Muchas de estas controversias son acerca de la atribución de significado a determinadas formulaciones normativas y pueden resolverse apelando a consensos más o menos establecidos dentro de la comunidad jurídica (con alegación de argumentos que no necesariamente aludan a principios ni tengan forzosamente un componente moral).

Las únicas controversias que serían relevantes para la crítica que aquí estoy analizando serían las que afecten a los criterios de validez jurídica (que forman una concreta regla de reconocimiento). ¿Pero de veras se dan tales controversias profundas en las prácticas de interpretación y aplicación del Derecho que conocemos?

Tomemos a modo de ejemplo una posible formulación simplificada de la regla de reconocimiento del sistema jurídico español. Ésta podría rezar más o menos como sigue: «Se considerarán Derecho español válido la Constitución de 1978 y todas las normas aceptadas por ella o creadas de acuerdo con los procedimientos que establece, sin que hayan sido derogadas». Esta idea, en el ámbito de la aplicación del Derecho, se concretaría en una serie de criterios ordenados jerárquicamente, en lo que se conocen como fuentes del Derecho. Un ejemplo de fuentes del Derecho sería éste: se aplicará a los casos a enjuiciar, en primer lugar, la constitución; en su defecto, las leyes en sentido amplio (con sus propias jerarquías: ley en sentido técnico, reglamentos, etc.); a falta de éstas, serán de aplicación las normas consuetudinarias; cuando la aplicación de éstas no sea posible, se aplicarán los principio generales del Derecho.

Ahora preguntémonos: ¿hay jueces que aplican las normas consuetudinarias por encima de las leyes?; ¿hay discrepancia acerca de que las leyes están subordinadas a la constitución? Planteemos la cuestión de una manera más general: ¿es concebible el funcionamiento normal (es decir, continuado y estable) de un sistema jurídico con una discusión permanente y profunda de tales criterios? Si se produjera de verdad esa discusión permanente y profunda respecto a los criterios de validez jurídica, estaríamos frente a supuestos patológicos de sistemas jurídicos (como alguna vez los llamó HART), y no serían precisamente casos paradigmáticos, que es lo que se exigiría para que la crítica de DWORKIN fuera plausible. Sencillamente, no podría funcionar durante demasiado tiempo un sistema en el que los criterios de validez jurídica estuvieran puestos en cuestión de manera profunda y permanente. 
Imaginemos que durante un cierto tiempo, en una determinada sociedad $S$, los jueces aplican de manera general las normas que emanan del parlamento elegido democráticamente. En un determinado momento, un grupo de personas se hace con el control del poder y empiezan a emitir normas destinadas a toda la población de $S$ y con la pretensión de que los jueces las apliquen. Puede ser que durante un cierto periodo de tiempo los jueces se hallen divididos acerca de si deben aplicar o no las normas emanadas de ese comité revolucionario (éste sería el caso patológico, que en muchas ocasiones va acompañado de una guerra civil). Pero pasada esa etapa convulsa, pueden suceder dos cosas: que los jueces apliquen generalmente las normas que emanan del parlamento o bien las del comité revolucionario. En este último supuesto, se habrá producido un cambio de la regla de reconocimiento de la sociedad $S$. Pero lo cierto es que resulta contra intuitivo pensar que la situación que he descrito como patológica es la normal, pero es la que parece describir DWORKIN.

Ello no quiere decir que no puedan existir discrepancias sobre el alcance de algunos criterios de validez que forman la regla de reconocimiento. Lo único que sostengo es que no pueden ser profundas y generalizadas, que sería lo que requeriría el argumento de DwORKIN para que la conclusión del mismo se siguiera efectivamente de sus premisas. Tampoco significa que no puedan haber casos dudosos relativos a si una determinada norma forma parte de un determinado sistema jurídico o si es aplicable. A esto último habría que añadir tan sólo una precisión acerca de la existencia de prácticas interpretativas. Teniendo en cuenta lo que, en relación con otro contexto, dice ANSCOMBE ${ }^{64}$, lo importante es que mientras los miembros del grupo reconozcan y comprendan un comportamiento dado como un comportamiento subsumible bajo la descripción relevante, la práctica de identificación de normas jurídicas, aun transformándose, sigue siendo la misma.

\subsection{La arbitrariedad de una regla de reconocimiento convencional}

Una crítica posible a la visión convencionalista de la regla de reconocimiento es que para que ésta se pueda considerar una convención, habría que admitir que es arbitraria, puesto que el rasgo de la arbitrariedad sería definitorio de las convenciones. Pero si hiciéramos esto, estaríamos obviando la importancia que desde el punto de vista social y político tendría la regla de reconocimiento. CELANO la ha expresado en estos términos:

«La idea de que la regla de reconocimiento sea arbitraria parece precipitada, casi irrisoria. La regla de reconocimiento especifica los criterios de identificación de aquello que constituye el Derecho válido. Ésta no es una cuestión asimilable a la decisión de si se debe conducir por la derecha o por la izquierda (un paradigma del problema de coordinación). La regla de reconocimiento es el resultado de conflictos políticos, institucionales, ideológicos; de revoluciones y golpes de estado [...]. Que ciertos criterios de validez son efectivamente aceptados y usados es un hecho histórico [...]. Se trata de un hecho que invoca valores y principios en conflicto. No es plausible la hipótesis según la cual $[. .$.$] consiste en$ algo arbitrario» ${ }^{65}$.

64 AnSCOMBe, 1957: 84 y ss. En el mismo sentido, $c f r$. Celano, 1995: 54.

65 Celano, 2003: 351. En términos parecidos se expresa, por ejemplo, SHAPIRO en el manuscrito de su último libro al que ya hice referencia. 
Este ataque parece a primera vista muy plausible. ¿Cómo vamos a tildar de arbitraria la decisión de los sujetos a la hora de identificar el Derecho de su comunidad cuando en ello parece estar en juego cuestiones valorativas tan importantes? Sin embargo, antes de sucumbir al aparente encanto de esta crítica no está de más empezar por preguntarnos qué se entiende por «arbitrario» en sede convencionalista ${ }^{66}$.

Se impone empezar recordando que la arbitrariedad de las convenciones no es igual a indiferencia ${ }^{67}$. Si una persona ha vivido veinte años en Londres y después traslada su residencia a Barcelona, no le resulta indiferente conducir por la izquierda de la calzada o por la derecha. Está aconstumbrada a conducir por la izquierda y preferiría seguir haciéndolo (por tanto, no le resulta indiferente la elección). Pero, justamente porque se da un problema de coordinación y existe ya una convención establecida en Barcelona de conducir por la derecha, esa persona tiene una razón para seguir la pauta de sus nuevos conciudadanos, a pesar de que claramente le resultaría más cómodo seguir con la práctica a la que estaba acostumbrada. El rasgo de la arbitrariedad de las convenciones, pues, se manifiesta no en la posible indiferencia con la que cada participante pueda afrontar las prácticas sociales relevantes, sino en el hecho de que exista más de una opción que resuelva el problema de coordinación que está en la base.

Pero, más allá de lo anterior, en esta línea crítica que comento hay una confusión entre lo que concierne a la existencia de un sistema jurídico y lo que tiene que ver con su identidad. Podría decirse que todos los elementos que están presentes en la cita transcrita de CELANO son importantes, pero no para la existencia de un sistema jurídico, sino para su identidad. El utilizar unos u otros de esos elementos daría lugar a la identificación de distintos sistemas jurídicos, pero no afectan a su existencia. Es decir, que el conjunto de criterios de identificación efectivamente usados por la población relevante sea $A$ (por ejemplo, definitorios de un régimen político democrático) o sea $B$ (propios de un régimen político autoritario) es relevante respecto a la identidad del sistema, pero que sea uno u otro no afecta para nada a su existencia (igual de «existentes» son los regímenes democráticos que los autoritarios, si se cumplen las condiciones requeridas) ${ }^{68}$. Lo único que muestra esta situación es que hay opciones distintas, y eso es lo fundamental para concluir que se da el rasgo de la arbitrariedad, en el sentido que aquí interesa. Por supuesto, valorativamente podemos preferir que el tipo de sistema jurídico existente pertenezca a la clase $A$ y no a la clase $B$, y eso es lo que nos molesta cuando calificamos tal elección de arbitraria. Pero el sentido de arbitrario que es relevante en relación con la existencia de la regla de reconocimiento (y, por tanto, de la existencia de los sistemas jurídicos) es que quienes se dedican profesionalmente a identificar el sistema jurídico utilicen los mismos criterios, teniendo la posibilidad de que éstos sean propios de un régimen democrático o de uno autoritario, incluyan los precedentes o no, establezcan un tipo de jerarquía normativa u otro, etcétera.

\footnotetext{
66 Para el concepto de arbritario, vid. MARMOR, 2006.

67 Cfr. LEWIS, 1969: 76-80.

68 Respecto a la identidad de los órdenes jurídicas y su vinculación justamente con estas cuestiones valorativas remito a VILAJOSANA, 1997.
} 


\subsection{La supuesta banalidad de la tesis convencionalista}

Una última crítica que voy a comentar es la que sostiene el carácter banal de la tesis convencionalista aplicada a la regla de reconocimiento. En concreto, esta crítica se refiere a la llamada condición de dependencia, entendida de este modo: en el caso de una convención, el hecho de que los demás se conformen porque los otros lo hacen es una de las razones por las que cada uno se conforma. Ésta es justamente una de las condiciones que destaqué al hablar de la existencia de una regla de reconocimiento como hecho convencional.

Pues bien, por ejemplo, B. CELANO afirma que el exigir esta condición puede resultar verosímil, pero banal. Sus palabras son:

«Se trata de una tesis empírica según la cual, en el caso de la regla de reconocimiento, cada uno de los funcionarios (cualesquiera que sean las razones por las que está convencido de que la regla debe seguirse, o por las que la sigue) piensa que no tendría mucho sentido atenerse a la regla, a menos que lo hiciesen todos (o casi todos) los demás. Lo cual es verosímil, pero banal» ${ }^{69}$.

En mi caso, estoy de acuerdo con que la tesis es verosímil y razonable (por eso la defiendo), pero no estoy seguro de comprender cuál sería en este punto el elemento negativo que incorporaría el rasgo de la banalidad. El propio CELANO da una pista acerca de qué sería una tesis banal. Se trataría de una tesis poco informativa, teóricamente no interesante y filosóficamente poco iluminadora ${ }^{70}$. Pero ¿la tesis convencionalista tiene estos rasgos?

Concentrémonos primero en el aspecto positivo de la tesis, que CELANO admite. La tesis es verosímil y razonable. Bien; si esto es así, ¿cómo hay que interpretar que muchos autores la discutan? ¿Por qué, como hemos visto, DwORKIN dedica un gran esfuerzo a intentar mostrar que no es posible una regla de reconocimiento convencional? Si fuera una tesis banal, parecería que cualquier persona razonable (y no seré yo quien diga que DwORKIN no lo es) la admitiría, aunque a renglón seguido añadiera que no aporta nada nuevo. Ya he dicho antes lo que pienso de esta condición de dependencia. Si nos centramos en el alcance concreto que aquí he dado a la regla de reconocimiento, hay que recordar que su existencia depende de las prácticas de identificación de un determinado sistema jurídico que se llevan a cabo en una determinada sociedad. Es el uso de criterios de identificación de un determinado sistema jurídico lo que está en juego (y no otra cosa) cuando se habla de dichas prácticas. Pero tales criterios deben ser los mismos si es que se pretende identificar el mismo sistema jurídico. Y si esto es así, se requiere de los participantes que tengan en cuenta los criterios usados por los demás. En esto consiste, como ya dije en su momento, el problema de coordinación que está en la base de la necesidad de que (al menos) los funcionarios usen los mismos criterios para identificar su sistema jurídico.

Tal vez, lo que se quiera decir con el término «banal» es que el fenómeno es circular. Pero eso, como ya comenté en su momento, lejos de preocuparnos nos da la pista

69 Celano, 2003: 353.

$70 \mathrm{Si}$ interpretamos a sensu contrario lo que se dice en CELANO, 2003: 347. 
para producir una explicación filosóficamente atractiva de cómo a través de reglas constitutivas se puede generar realidad social, como sucede con la existencia del dinero y como, en mi opinión, acaece con la existencia del Derecho ${ }^{71}$.

A pesar de lo que acabo de decir, se podría obviar que haya alternativas como la que ofrece DwORKIN y que la explicación de fenómenos circulares como se propone aquí no sea filosóficamente satisfactoria, pero entonces todavía quedaría en pie saber en qué consiste una explicación filosófica no banal. Y aquí es donde uno tiene la tentación de sostener, con WiTTGENSTEIN, que toda tesis filosófica es, en algún sentido, poco informativa. Lo que hacemos al filosofar es, a lo sumo, algo parecido a modificar la posición de los libros en una estantería:

«Algunos de los mayores logros en filosofía sólo podrían compararse con el hecho de coger algunos libros que parecían tener que estar juntos y colocarlos sobre estantes diferentes, no siendo definitivo sobre sus posiciones más que el hecho de que ya no están uno al lado del otro. El observador que no conoce la dificultad de la tarea es fácil que piense en tal caso que no se ha conseguido nada en absoluto» ${ }^{72}$.

\section{BIBLIOGRAFÍA}

Anscombe, G. E. M., 1957: Intention, Oxford, Blackwell. Traducción castellana de A. I. STELLINO, Intención, Barcelona, Paidós.

- 1958: «On Brute Facts», Analysis, 18, incluido en Ethics, Religion and Politics. The Collected Philosophical Papers of G. E. M. Anscombe, vol. III, Oxford, Basil Blackwell, 1981.

Austin, J., 1832: The Province of Jurisprudence Determined, en W. E. RumbLE (ed.), Cambridge, Cambridge University Press, 1995. Traducción castellana de J. R. PARAMO, El objeto de la jurisprudencia, Madrid, Centro de Estudios Políticos y Constitucionales, 2002.

BAYÓN, J. C., 2001: «El contenido mínimo del positivismo jurídico», inédito.

BuLYGIN, E., 1991: «Regla de reconocimiento: ¿Norma de obligación o criterio conceptual? Réplica a Juan Ruiz Manero», Doxa, vol. 9, 311-318.

Celano, B., 1995: «Consuetudini, convenzioni», en P. Comanducci y R. Guastini (eds.), Analisi e diritto, Torino, Giappichelli. Traducción castellana de J. J. MoRESO, por donde se cita: «Costumbres, convenciones», en Dos estudios sobre la costumbre, México, Fontamara, 2000, 15-77.

— 2003: «La regola di riconoscimento è una convenzione?», Ragion Pratica, núm. 21, 347-360.

Coleman, J. L., 1998: «Incorporationism, Conventionality, and the Practical Diference Thesis», Legal Theory, vol. 4, 381-425.

- 2001: The Practice of Principle: In Defence of a Pragmatism Approach to Legal Theory, Oxford, Oxford University Press.

DworkIN, R., 1971, 1977: Taking Rights Seriously, London, Duckworth. Traducción castellana de M. Gustavino, Los derechos en serio, Barcelona, Ariel, 1984.

- 1986: Law's Empire. Cambridge, Mass., Harvard University Press.

GARZÓN, E., 1993: «Algo más acerca de la relación entre el Derecho y la moral», incluido en Derecho, Ética y Política, Madrid, CEC, 317-335.

71 El propio CELANO ha admitido una circularidad no viciosa en relación con su visión de las normas consuetudinarias como reglas sociales. Cfr. CELANO, 1995.

72 WitTgenstein, 1958: 75-76. Obviamente, Celano no estaría entre quienes desconocen esa dificultad, dada su más que probada competencia filosófica. 
Gilbert, M., 1989: On Social Facts, Princeton, Princeton University Press.

GreEn, L., 1988: The Authority of the State, Oxford, University Press.

GreenberG, M., 2004: «How Facts Make Law», Legal Theory, 10, 157-198.

Hart, H. L. A., 1961: The Concept of Law, Oxford, Oxford University Press. Traducción castellana de G. R. CARrio, El concepto de Derecho, Buenos Aires, Abeledo-Perrot, 1963.

- 1994: «Postscript to The Concept of Law», en P. Bulloch y J. RAz (eds.), 2. a ed., Oxford, Oxford University Press.

Hartogh, G. D., 2002: Mutual Expectations. A Conventionalist Theory of Law, The HagueLondon-New York, Kluwer.

JACKSON, J., 1988: «Hart and the Concept of Fact», en P. LEITH y P. IngRAM (eds.), The Jurisprudence of orthodoxy: Queen's University Essays on H. L. A. Hart, London, Routledge.

Kelsen, H., 1960: Reine Rechtslehre (2. ed.), Wien, Frans Deuticke. Traducción castellana de R. J. Vernengo, Teoría pura del Derecho, México, UNAM, 1979.

LagerSPeTZ, E., 1995: The Opposite Mirrors. An Essay on the Conventionalist Theory of Institutions, Dordrecht, Kluwer.

LeITER, B., 2001: «Legal Realism, Hard Positivism, and the Limits of Conceptual Analysis», en J. Coleman (ed.): Hart's Postcript. Essays on the Postscript to the Concept of Law, Oxford, Oxford University Press, 355-370.

LEWIS, D., 1969: Convention. A philosophical Study, Oxford, Basil Blackwell.

MacCormick y Weinberger, 1986: An Institutional Theory of Law. New Approches to Legal Positivism, Dordrecht, Reidel.

Marmor, A. (ed.), 1996: «On Convention», Synthese, 107, 349-371.

- 2001a: «Legal Conventionalism», en J. Coleman (ed.), Hart's Postcript. Essays on the Postscript to the Concept of Law, Oxford, Oxford University Press, 193-217.

- 2001b: Positive Law and Objective Values, Oxford, Clarendon Press.

Mendonca y Guibourg, 2004: La odisea constitucional. Constitución, teoría y método, MadridBarcelona, Marcial Pons.

Moreso, J. J., y Vilajosana, J. M., 2004: Introducción a la Teoría del Derecho, Madrid-Barcelona, Marcial Pons.

NarváEz, M., 2004: Wittgenstein y la teoría del Derecho. Una senda para el convencionalismo jurídico, Madrid-Barcelona, Marcial Pons.

NETA, R., 2004: «On the normative significance of brute facts», Legal Theory, núm. 10, 199-214.

NinO, C. S., 1982: Introducción al análisis del Derecho, Barcelona, Ariel.

Olivecrona, K., 1939: Law as Fact, Copenhague, Einar Munksgaard.

OPALEK, K., 1971: «Law as Social Phenomenon», ARSP, vol. 1, 37-53.

PeCzenik, A., y Hage, J., 1999: «Conocimiento jurídico, ¿'sobre qué?», Doxa, núm. 22, 25-48.

Postema, G. J., 1982: «Coordination and Convention at the Foundations of Law», Journal of Legal Studies, vol. XI, 165-203.

— 2004: «Melody and Law's Mindfulness of Time», Ratio Iuris, vol. 17, $203-222$.

PRIETO SANCHÍs, 2008: «Identificación y justificación del Derecho», Anuario de Filosofía del Derecho, vol. XXV, 487-506.

RAZ, J., 1979: The Authority of Law, Oxford, Oxford University Press. Traducción castellana de R. TAmayo, La autoridad del Derecho, México, UNAM, 1982.

RuIZ MANERO, J., 1990: Jurisdicción y normas, Madrid, CEC.

- 1991: «Normas independientes, criterios conceptuales y trucos verbales; Respuesta a Eugenio Bulygin», Doxa, vol. 9, 281-293. 
SEARLE, J. R., 1995: The Construction of Social Reality. Traducción castellana de A. DOMENECH, La construcción de la realidad social, Barcelona, Paidós, 1997.

Shapiro, S. J., 2001: «On Hart's Way Out», en J. Coleman (ed.), Hart's Postcript. Essays on the Postscript to the Concept of Law, Oxford, Oxford University Press, 149-191.

ToH, K., 2008: «An Argument against the Social Fact Thesis (and some additional preliminary steps towards a new conception of legal positivism», Law and Philosophy, núm. 27, 445-504.

Tomás De AQuino, 1997: Suma de teología, 2. ed., Madrid, Biblioteca de Autores Cristianos.

Tuzet, G., 2007: «The Social Reality of Law», en P. Comanducci y R. GuASTini (eds.), Analisi e diritto, Torino, Giappichelli, 179-198.

Ullmann-Margalit, E., 1977: The Emergence of Norms, Oxford, Clarendon Press.

Vilajosana, J. M., 1996: «Towards a material criterion of identity of a legal order», Rechtstheorie, vol. 27, 45-64.

- 1997: El significado político del Derecho, México, Fontamara.

— 2003: «Hechos sociales y Derecho», en E. DiciotTi y V. VelluzZI (eds.), Ordinamento giuridico, sovranità, diritti, Torino, Giappichelli, 41-63.

— 2006: «El positivismo jurídico convencionalista», en J. A. RAmos PAsCuA y M. A. Rodilla (eds.), El positivismo jurídico a examen. Estudios en homenaje a José Delgado Pinto, Salamanca, Ediciones Universidad de Salamanca, 521-538.

- 2007: Identificación y justificación del Derecho, Madrid-Barcelona-Buenos Aires, Marcial Pons.

- 2008: «A las puertas del paraíso. Respuesta a Luis Prieto Sanchís», Anuario de Filosofía del Derecho, vol. XXV, 507-536.

Von Wright, G. H., 1963: Norm and Action. A Logical Enquiry, London, Routledge and Kegan Paul. Traducción castellana de P. GARCíA, Norma y acción. Una investigación lógica, Madrid, Tecnos, 1971.

Wittgenstein, L., 1958: The Blue and Brown Books, Oxford, Basil Blackwell \& Mott, Ltd. (2. ${ }^{a}$ ed.). Traducción castellana de F. GRACIA Guillén, Cuadernos azul y marrón, Madrid, Tecnos, 1968.

Zipursky, B. C., 2001: «The Model of Social Facts», en J. Coleman (ed.). Hart's Postcript. Essays on the Postscript to the Concept of Law, Oxford, Oxford University Press, 219-270. 